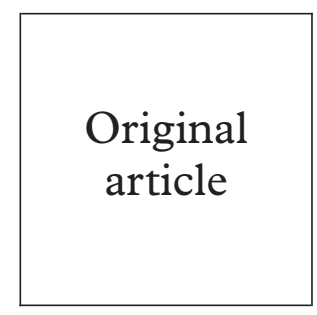

National Institute for Medical Research, Mwanza, Tanzania

J Todd

J Mngara

J Changalucha

F Mosha

London School of Hygiene and Tropical Medicine, London, UK J Todd

H Grosskurth

P Mayaud

D Mabey

R Hayes

African Medical and Research Foundation (AMREF), Mwanza,

Tanzania

K Munguti

H Grosskurth

P Mayaud

A Gavyole

Regional Medical Office, Mwanza,

Tanzania

A Gavyole

Correspondence to:

$\mathrm{J}$ Todd, London School of

Hygiene and Tropical

Medicine, Keppel Street,

London WC1E 7HT

j.todd@1shtm.ub

Accepted for publication

14 November 2000

website

extra

Additional tables

appear on the

STI website.

www.sextransinf.com

\title{
Risk factors for active syphilis and TPHA seroconversion in a rural African population
}

\author{
J Todd, K Munguti, H Grosskurth, J Mngara, J Changalucha, P Mayaud, F Mosha, \\ A Gavyole, D Mabey, R Hayes
}

Objectives: Syphilis is an important cause of morbidity in sub-Saharan Africa, and a cofactor for the sexual transmission of HIV. A better understanding of the prevalence and risk factors of syphilis in African populations would help to formulate effective interventions for its prevention and treatment.

Methods: The prevalence and incidence of syphilis were obtained from a cohort recruited in Mwanza, Tanzania. Two unmatched case-control studies nested within the cohort provide information on potential risk factors.

Results: The prevalence of active syphilis (TPHA positive and RPR positive any titre) was $7.5 \%$ in men and $9.1 \%$ in women, but in youths (aged 15-19 years) the prevalence was higher in women $(6.6 \%)$ than in men $(2.0 \%)$. The incidence of TPHA seroconversion was highest in women aged $15-19$ at 3.4\% per year, and around $2 \%$ per year at all ages among men. A higher prevalence of syphilis was found in those currently divorced or widowed (men: $\mathrm{OR}=1.61$, women: $\mathrm{OR}=2.78$ ), and those previously divorced or widowed (men: $\mathrm{OR}=1.51$, women: $\mathrm{OR}=1.85$ ). Among men, prevalence was associated with lack of circumcision $(\mathrm{OR}=1.89)$, traditional religion $(\mathrm{OR}=1.55)$, and reporting five or more partners during the past year $(\mathrm{OR}=1.81)$ while incidence was associated with no primary education $(\mathrm{OR}=2.17)$, farming $(\mathrm{OR}=3.85)$, and a self perceived high risk of STD $(\mathrm{OR}=3.56)$. In women, prevalence was associated with no primary education $(\mathrm{OR}=2.13)$, early sexual debut $(\mathrm{OR}=1.59)$, and a self perceived high risk of STD $(\mathrm{OR}=3.57)$, while incidence was associated with living away from the community $(\mathrm{OR}=2.72)$.

Conclusion: The prevalence and incidence of syphilis remain high in this rural African population. More effort is needed to promote safer sexual behaviour, and to provide effective, accessible treatment. The high incidence of syphilis in young women calls for sexual health interventions targeted at adolescents.

(Sex Transm Inf 2001;77:37-45)

Keywords: syphilis; risk factors; Africa

\section{Introduction}

Over the past few decades, the prevalence and incidence of syphilis in the developed world have fallen steeply due to improved access to health care, effective control programmes, and efficacious treatment. ${ }^{12}$ In many developing countries, however, syphilis remains a major public health problem, with an estimated 12 million cases per year worldwide, of which 4 million occur in Africa. ${ }^{3}$ Syphilis is an important cause of morbidity and if untreated has many serious sequelae, particularly among women and their newborn infants. ${ }^{5-7}$ In addition, syphilis and other sexually transmitted diseases (STDs), particularly those resulting in genital ulceration, are associated with enhanced sexual transmission of HIV. ${ }^{8} 9$

Serological surveys in Tanzania have shown that the prevalence of active syphilis (TPHA positive and RPR positive any titre) remains unacceptably high, with adult prevalences ranging from $5.9 \%$ in Kagera to $12.8 \%$ in roadside settlements in Mwanza. ${ }^{10-12}$ A previous study in Mwanza Region in 1990 showed that the prevalence of active syphilis was $8.1 \%$ in males and $9.4 \%$ in females. ${ }^{10}$ Risk factor analysis showed an association between syphilis and a higher number of sexual partners in both sexes. A higher prevalence of syphilis was also observed among uncircumcised men, men who were widowed, divorced, or separated, and women with a lower level of education. ${ }^{13}$

In Tanzania, as in many other parts of Africa, measures to control syphilis have not been rigorously pursued. Until the mid-1990s, there was little health education to raise awareness of STDs or to encourage prompt attendance for treatment. Although treatment for syphilis is cheap and effective, access to treatment is difficult for many people living in rural areas. Antenatal screening and treatment for syphilis is advocated for syphilis control, ${ }^{14}$ but has not been widely implemented. In recent years syndromic management of STDs, as advocated by the World Health Organization, has been implemented in many developing countries. Syndromic management of STDs involves treating patients at their first visit to the health facility according to their signs and symptoms. The aim is to provide immediate and effective treatment for those pathogens most commonly associated with each clinical syndrome. In a community randomised trial in Mwanza, syndromic treatment services for STDs were shown to reduce the incidence of HIV in the general population by $38 \%$, and the prevalence of active syphilis by $29 \% .{ }^{15-17}$

Despite the impact observed in the Mwanza intervention trial, the prevalence of active syphilis remained unacceptably high even in 
communities where syndromic treatment was provided ${ }^{16}$ suggesting that more intensive control strategies are needed. The identification of specific risk factors for syphilis might assist in developing interventions or targeting them to particular risk groups. Two case-control studies, nested within the Mwanza intervention trial, allowed us to investigate risk factors for HIV and other STDs in this population. An analysis of risk factors for HIV infection has been reported previously, ${ }^{18}$ and demonstrated that some individuals are at risk through having a large number of sexual partners, while others are at risk because of the characteristics of their spouses. In this paper, we present data on risk factors for prevalent cases of active syphilis, and for incident cases of TPHA seroconversion, in rural Mwanza.

\section{Methods}

Mwanza Region is situated on the southern shores of Lake Victoria, and has a population of approximately 3 million. Between 1991 and 1994 , a community randomised trial was conducted in 12 large rural communities to measure the impact of improved STD treatment services delivered through government primary healthcare units. The design and evaluation of the intervention have been reported previously. ${ }^{1519}$ Briefly, in 1991-2 before the implementation of the programme a baseline survey was carried out in a cohort of approximately 1000 adults aged 15-54 years selected randomly from each of the 12 study communities. The 12 communities were matched into six pairs and one community from each pair was randomly selected to receive the intervention immediately, the other community receiving the intervention following the end of the trial. Two years later in a follow up survey the members of the cohort were traced, re-interviewed and re-examined for HIV and STDs, and the effects of the intervention were measured allowing for the community randomised design.

At both baseline and follow up surveys, a sample of venous blood was taken from consenting subjects which was tested for syphilis in the field using the rapid plasma reagin (RPR) test (VD25 VDRL, Murex, Dartford, UK). RPR positive subjects were treated immediately with benzathine penicillin. Sera were transported to a laboratory and all were tested using the Treponema pallidum haemagglutination assay (TPHA, Fujirebio, Tokyo, Japan). TPHA positive sera were retested using the same RPR test, and RPR titres were recorded. At the baseline survey, three nested subgroups were defined for the markers of syphilis: TPHA positivity was regarded as a lifetime marker of past or present syphilis infection; TPHA positivity together with RPR positivity as an indicator of active syphilis; and TPHA positivity with an RPR titre of $1: 8$ or greater as an indicator of high titre active syphilis. At follow up, TPHA seroincidence was taken as a marker of incident syphilis occurring over 2 years among those initially TPHA negative.
Following each survey, an unmatched casecontrol study was undertaken to examine risk factors for syphilis. At baseline, cases were defined as individuals with active syphilis (TPHA+/RPR+ any titre). A random sample of such cases was selected for inclusion in the first case-control study, along with a 1 in 8 random sample of controls from the remainder of the cohort. The first case-control study took place from March to May 1993, between 5 and 16 months after the baseline survey. A second case-control study took place from August 1994 to February 1995, between 3 and 6 months after the follow up survey. Cases were defined as subjects who had seroconverted to TPHA (TPHA - at baseline, TPHA+ at follow up), and the controls were a 1 in 8 random sample from persistently TPHA negative members of the cohort. The first case-control study was conducted to investigate risk factors for prevalent cases of active syphilis at baseline, while the second case-control study was conducted to investigate risk factors for incident syphilis occurring during follow up.

In both case-control studies, informed consent was obtained and a structured questionnaire was administered to ascertain sociodemographic characteristics and detailed information on sexual behaviour and perception of risk. The case-control questionnaires were designed in English, translated into Ki-Swahili, back translated into English, and pretested in a pilot study. Sexual partners were classified as spouses (marital partners), regular partners (based on the Swahili words for mistress and concubine), or casual partners (including commercial sex workers). Nonmedical personnel were trained in interview techniques and were unaware of the case or control status of the participants. All participants were offered treatment by a clinician for any medical conditions reported following the interview.

At both rounds (baseline and follow up), information from both the main survey questionnaire and the case-control questionnaire were combined for analysis. In the analysis, each sex was considered separately. Communities were classified by geographic location as roadside settlements, rural villages, or lake island communities. Risk factors for syphilis have been broadly categorised as either background or "proximate" factors. The former category consists of social, economic, and demographic factors, while the latter includes various markers of sexual activity. Marital status was categorised in four groups: those never married, those married and never divorced or widowed, those married but previously divorced or widowed, and those currently divorced or widowed.

Odds ratios (OR), adjusted for age group (15-19, 20-24, 25-34, 35-44, 45-54) and community of residence, were estimated for all risk factors using logistic regression. For background factors, no adjustment was made for other potential confounders, since the aim was to describe the relative risk in different groups of individuals rather than to isolate the specific effect of a particular variable. ORs for proxi- 
Table 1 Prevalence and incidence of serological markers of syphilis in Mwanza Region, Tanzania, by age at baseline and $\operatorname{sex}$

\begin{tabular}{|c|c|c|c|c|c|c|}
\hline & \multicolumn{4}{|c|}{ Baseline prevalence } & \multicolumn{2}{|c|}{ Incidence over 2 years } \\
\hline & No & TPHA +ve & $\begin{array}{l}\text { TPHA +ve RPR } \\
\text { +ve }\end{array}$ & $\begin{array}{l}\text { TPHA +ve RPR } \\
\geqslant 1: 8\end{array}$ & $\mathrm{No}^{\star}$ & $T P H A+v e$ \\
\hline \multicolumn{7}{|l|}{ Males } \\
\hline $15-19$ years & 1043 & $33(3.2 \%)$ & $21(2.0 \%)$ & $17(1.6 \%)$ & 694 & $33(4.8 \%)$ \\
\hline $20-24$ years & 1053 & $125(11.9 \%)$ & $84(8.0 \%)$ & $76(7.2 \%)$ & 638 & $28(4.4 \%)$ \\
\hline $25-34$ years & 1817 & $303(16.7 \%)$ & $165(9.1 \%)$ & $129(7.1 \%)$ & 999 & $45(4.5 \%)$ \\
\hline $35-44$ years & 1065 & $223(20.9 \%)$ & $116(10.9 \%)$ & $77(7.2 \%)$ & 620 & $20(3.2 \%)$ \\
\hline $45-54$ years & 978 & $173(17.7 \%)$ & $70(7.2 \%)$ & $45(4.6 \%)$ & 634 & $22(3.5 \%)$ \\
\hline Total & 5956 & $857(14.4 \%)$ & $456(7.7 \%)$ & $344(5.8 \%)$ & 3585 & $148(4.1 \%)$ \\
\hline \multicolumn{7}{|l|}{ Females } \\
\hline $15-19$ years & 1175 & $103(8.8 \%)$ & $78(6.6 \%)$ & $68(5.8 \%)$ & 647 & $44(6.8 \%)$ \\
\hline $20-24$ years & 1365 & $207(15.2 \%)$ & $144(10.5 \%)$ & $104(7.6 \%)$ & 767 & $21(2.7 \%)$ \\
\hline $25-34$ years & 1968 & $375(19.1 \%)$ & $215(10.9 \%)$ & $147(7.5 \%)$ & 1092 & $20(1.8 \%)$ \\
\hline $35-44$ years & 1174 & $228(19.4 \%)$ & $99(8.4 \%)$ & $65(5.5 \%)$ & 735 & $17(2.3 \%)$ \\
\hline $45-54$ years & 948 & $157(16.6 \%)$ & $69(7.3 \%)$ & $43(4.5 \%)$ & 596 & $16(2.7 \%)$ \\
\hline Total & 6630 & $1070(16.1 \%)$ & $605(9.1 \%)$ & $427(6.4 \%)$ & 3837 & $118(3.1 \%)$ \\
\hline
\end{tabular}

^Number seen at follow up and TPHA negative at baseline.

mate factors were adjusted for confounders, by fitting a logistic regression model including all variables that were statistically significant after adjustment for age group and community. Statistical significance was assessed using the likelihood ratio test. Adjusted ORs were used to estimate the population attributable fraction (PAF) of syphilis cases associated with each risk factor according to the method of Bruzzi et $a l .{ }^{20}$ Dbase 4 (Borland) was used for data entry and stata 5.0 (Stata Corp) for the analysis. Ethical clearance for the study was obtained from NIMR ethics committee in Dar es Salaam.

\section{Results}

In the baseline survey of the main cohort, a total of 857 men (14\%) and 1070 women $(16 \%)$ were TPHA positive (tables 1 and w 1 on the $S T I$ website). Of these, 456 men $(7.7 \%$ of cohort) and 605 women $(9.1 \%)$ had active syphilis (TPHA+/RPR+), while 344 men $(5.8 \%)$ and 427 women $(6.4 \%)$ had high titre active syphilis (TPHA+/RPR titre $\geqslant 1: 8$ ).

In men, the prevalence of active syphilis was relatively low in the youngest age group, but remained at $7-11 \%$ from age 20 upwards. As a marker of cumulative incidence, TPHA seropositivity continued to increase with age to a peak of around $20 \%$ in men aged $35-44$. A similar pattern was seen in women, except that prevalence peaked at a younger age, and the prevalence of active syphilis in those aged 15-19 was much higher in women $(6.6 \%)$ than in men $(2.0 \%)$. Overall, $771 / 1927(40 \%)$ of those who were TPHA positive had high titre active syphilis, but this proportion ranged from $68 / 103(66 \%)$ among women aged $15-19$ to $88 / 330(27 \%)$ among men and women aged 45-54.

Of those initially TPHA negative, 148 men $(4.1 \%)$ and 118 women $(3.1 \%)$ seroconverted during 2 years of follow up, equivalent to an annual incidence of $1.8 \%$ (tables 1 and w 1 on website). Among men, TPHA seroincidence was relatively stable at all ages. In women, by contrast, incidence was very high in those aged $15-19$ ( $6.8 \%$ over 2 years), falling to lower levels from age 20 . When questioned at the follow up survey, only $50(19 \%)$ of the TPHA seroconverters (34 men and 16 women) reported symptoms of genital ulcer during the 2 years of follow up.

The prevalences of all markers of syphilis were highest in roadside settlements, intermediate in rural villages, and much lower in island communities (table w1 on website). In each of these geographical strata, the prevalence of infection was somewhat higher in women than men, although seroincidence was lower in women.

For the first study, 651 cases and 1383 controls were selected of whom $462(71 \%)$ and $1048(76 \%)$ participated (table w2 on website). In the second study 262 cases and 932 controls were selected, of whom $210(80 \%)$ and 708 $(76 \%)$ participated. In both studies nonparticipation was due mainly to the subject not being found $(10 \%$ of those selected had moved from the community and 5\% were travelling at the time of the study). Only 11 people actively refused to participate in the first case-control study and three in the second case-control study, while 54 people were excluded because of doubts about their identity in the first study and 45 in the second study. No female incident cases from one community (island intervention community) were found in the second study.

\section{BACKGROUND RISK FACTORS FOR ACTIVE}

SYPHILIS

From the first case-control study, there was a highly significant association with age in both sexes (tables 2 and w3 on website). A higher level of education was associated with a lower prevalence of active syphilis among women, while there was no clear trend in men. In both sexes, there was a non-significant trend towards lower prevalence among those who had travelled to Mwanza town during the past year. In men but not in women, prevalence was significantly higher among those with "other" (mostly traditional) religions.

Marital status was associated with active syphilis in both men and women, with the lowest prevalence in those who had never married, and the highest prevalence in those who were divorced or widowed, either currently or previously. Among currently married men, the prevalence of syphilis was higher in those 
Table 2 Risk factors for active syphilis: odds ratios for selected sociodemographic factors, by sex (first case-control study)

\begin{tabular}{|c|c|c|c|c|c|c|}
\hline \multirow[b]{2}{*}{ Variables } & \multicolumn{2}{|l|}{ Males } & \multirow{2}{*}{$\begin{array}{l}\text { Adjusted OR } \\
(95 \% \mathrm{CI})\end{array}$} & \multicolumn{2}{|c|}{ Females } & \multirow{2}{*}{$\begin{array}{l}\text { Adjusted } \\
\text { OR* }(95 \% \text { CI })\end{array}$} \\
\hline & Case & Control & & Case & Control & \\
\hline Number participated & 226 & 493 & & 236 & 555 & \\
\hline \multicolumn{7}{|l|}{ Age (years) } \\
\hline $15-19$ & 10 & 109 & $\mathrm{p}<0.001$ & 27 & 96 & $\mathrm{p}=0.007$ \\
\hline $20-24$ & 39 & 78 & $5.67(2.63-12.2)$ & 59 & 104 & $2.23(1.29-3.84)$ \\
\hline $25-34$ & 94 & 137 & $7.68(3.78-15.6)$ & 81 & 158 & $1.83(1.10-3.06)$ \\
\hline $35-44$ & 48 & 75 & $6.80(3.20-14.4)$ & 41 & 106 & $1.34(0.76-2.36)$ \\
\hline $45-54$ & 35 & 94 & $4.30(1.99-9.26)$ & 28 & 91 & $1.04(0.57-1.92)$ \\
\hline \multicolumn{7}{|l|}{ Education $\dagger$} \\
\hline None/adult & 45 & 78 & $\mathrm{p}=0.10$ & 128 & 241 & $\mathrm{p}<0.001$ \\
\hline Primary $<4$ years & 44 & 79 & $1.19(0.69-2.08)$ & 24 & 50 & $0.70(0.40-1.22)$ \\
\hline Primary $4+$ years & 137 & 336 & $0.74(0.46-1.18)$ & 84 & 264 & $0.47(0.32-0.69)$ \\
\hline \multicolumn{7}{|l|}{ Religion } \\
\hline Catholic & 79 & 192 & $\mathrm{p}=0.04$ & 97 & 222 & $\mathrm{p}=0.11$ \\
\hline Moslem & 8 & 21 & $0.87(0.34-2.15)$ & 5 & 27 & $0.44(0.16-1.22)$ \\
\hline Protestant & 48 & 133 & $0.82(0.52-1.30)$ & 57 & 151 & $0.83(0.55-1.24)$ \\
\hline Other & 91 & 147 & $1.55(1.03-2.33)$ & 77 & 154 & $1.24(0.83-1.86)$ \\
\hline \multicolumn{7}{|l|}{ Current marital status: } \\
\hline Married, never divorced/widowed & 107 & 229 & $\mathrm{p}=0.035$ & 119 & 333 & $\mathrm{p}<0.001$ \\
\hline Married, previous divorce/widow & 80 & 128 & $1.51(1.03-2.22)$ & 68 & 122 & $1.85(1.25-2.73)$ \\
\hline Currently widowed/divorced & 17 & 22 & $1.61(0.79-3.29)$ & 37 & 45 & $2.78(1.65-4.69)$ \\
\hline Never married & 22 & 113 & $0.66(0.36-1.21)$ & 12 & 54 & $0.73(0.34-1.57)$ \\
\hline \multicolumn{7}{|l|}{ Age at first marriage (years) $† \ddagger$} \\
\hline Under 18 & 21 & 31 & $\mathrm{p}=0.16$ & 116 & 206 & $\mathrm{p}=0.01$ \\
\hline $18-20$ & 71 & 117 & $0.85(0.43-1.68)$ & 57 & 199 & $0.45(0.30-0.67)$ \\
\hline 21 or more & 99 & 189 & $0.68(0.35-1.32)$ & 19 & 37 & $0.85(0.45-1.58)$ \\
\hline \multicolumn{7}{|l|}{ Spouse widowed or divorced $\ddagger$} \\
\hline No & 111 & 268 & $\mathrm{p}<0.001$ & 120 & 312 & $\mathrm{p}=0.3$ \\
\hline Yes & 76 & 89 & $2.15(1.42-3.24)$ & 67 & 143 & $1.23(0.85-1.79)$ \\
\hline
\end{tabular}

* Odds ratio adjusted for age and community of residence.

†Significance calculated with test for trend.

$\ddagger$ Only applicable to those currently married.

whose spouses were previously widowed or divorced, and, among currently married women, marriage before 18 years of age was associated with a higher prevalence of syphilis. There was no significant association with polygamy: odds ratios for those in polygamous marriages compared with those in monogamous marriages were $\mathrm{OR}=0.90 \quad(95 \% \mathrm{CI}$ : $0.51-1.58$ ) for men, and $\mathrm{OR}=1.06$ (CI: $0.70-1.61$ ) for women (data not shown). With about $30 \%$ of controls previously or currently divorced or widowed, among both men and women, our results imply a population attributable fraction (PAF) for active syphilis associated with marital dissolution of about $19 \%$.

BACKGROUND RISK FACTORS FOR SYPHILIS

SEROINCIDENCE

From the second case-control study, age was significantly associated with syphilis incidence in women but not in men (tables 3 and $\mathrm{w} 4$ on website). A higher level of education was associated with a lower incidence of syphilis in men, while there was no clear trend in women. The relatively small subgroup of men with nonfarming occupations were at significantly lower risk of incident syphilis. Women who had lived away from their community during the past 2 years were at significantly higher risk of incident syphilis, with a similar trend among men.

Among men who were currently or previously widowed or divorced, the incidence of syphilis was higher, but not significantly so, although in married men who had been separated from their spouse during the past 2 years, a similar effect $(\mathrm{OR}=1.96)$ was significant. No such association was seen among women. There was no significant association with polygamy: odds ratios for those in polygamous marriages compared with those in monogamous marriages were: $\mathrm{OR}=1.02$ (CI: 0.47-2.23) for men, and $\mathrm{OR}=1.06$ (CI: 0.54-2.09) for women (data not shown).

\section{PROXIMATE RISK FACTORS AMONG MEN}

There was a highly significant association between male circumcision and active syphilis (tables 4 and w5 on website). After adjustment for confounders, prevalence among circumcised men was about half that in uncircumcised men. With about $28 \%$ of controls circumcised, this would imply a PAF of $36 \%$ for active syphilis attributable to lack of circumcision among men. A similar trend was observed for seroincident syphilis, but this association was not significant.

The reported number of lifetime sexual partners was not associated with either active syphilis or TPHA seroincidence. However, there was an increased prevalence of active syphilis among those reporting five or more sexual partners during the past year. A similar though non-significant trend was observed for incident syphilis. There was no association between the prevalence or incidence of syphilis and reported numbers of casual sexual partners, other types of sexual partner (data not shown), or age at first sexual intercourse.

Condom use was relatively uncommon, and was not significantly associated with syphilis on adjusted analysis. The perceived risk of acquiring an STD was not associated with the prevalence of active syphilis, but was strongly associated with incident syphilis, an association which persisted after adjustment for confounders.

PROXIMATE RISK FACTORS AMONG WOMEN Among women, there was a significant association between reported number of lifetime 
Table 3 Risk factors for incident syphilis: odds ratios for selected sociodemographic factors, by sex (second case-control study)

\begin{tabular}{|c|c|c|c|c|c|c|}
\hline \multirow[b]{2}{*}{ Variables } & \multicolumn{2}{|c|}{ Males } & \multirow{2}{*}{$\begin{array}{l}\text { Adjusted } O R^{*} \\
(95 \% \mathrm{CI})\end{array}$} & \multicolumn{2}{|c|}{ Females } & \multirow{2}{*}{$\begin{array}{l}\text { Adjusted } O R^{*} \\
(95 \% \mathrm{CI})\end{array}$} \\
\hline & Case & Control & & Case & Control & \\
\hline Number participated & 119 & 367 & & 91 & 341 & \\
\hline \multicolumn{7}{|l|}{ Age at baseline (years) } \\
\hline $15-19$ & 27 & 61 & $\mathrm{p}=0.5$ & 37 & 47 & $\mathrm{p}<0.001$ \\
\hline $20-24$ & 20 & 57 & $0.97(0.46-2.04)$ & 13 & 68 & $0.25(0.12-0.53)$ \\
\hline $25-34$ & 35 & 108 & $0.78(0.41-1.46)$ & 17 & 100 & $0.21(0.11-0.43)$ \\
\hline $35-44$ & 17 & 66 & $0.60(0.29-1.25)$ & 10 & 64 & $0.22(0.10-0.51)$ \\
\hline $45-54$ & 20 & 75 & $0.62(0.31-1.25)$ & 14 & 62 & $0.28(0.13-0.60)$ \\
\hline \multicolumn{7}{|l|}{ Education $\dagger$} \\
\hline None/adult & 29 & 55 & $\mathrm{p}=0.016$ & 36 & 155 & $\mathrm{p}=0.5$ \\
\hline Primary $1-3$ years & 11 & 43 & $0.49(0.21-1.14)$ & 11 & 23 & $1.86(0.74-4.68)$ \\
\hline Primary $4+$ years & 79 & 269 & $0.46(0.25-0.84)$ & 44 & 163 & $0.80(0.41-1.54)$ \\
\hline \multicolumn{7}{|l|}{ Main current ocupation } \\
\hline Farmer & 114 & 315 & $\mathrm{p}=0.002$ & 85 & 322 & $\mathrm{p}=0.9$ \\
\hline Other & 5 & 52 & $0.26(0.10-0.69)$ & 6 & 19 & $0.95(0.33-2.69)$ \\
\hline \multicolumn{7}{|c|}{ Lived away from present community in past 2 years } \\
\hline No & 93 & 316 & $\mathrm{p}=0.07$ & 66 & 305 & $\mathrm{p}<0.003$ \\
\hline Yes & 26 & 51 & $1.69(0.96-2.95)$ & 25 & 36 & $2.72(1.41-5.25)$ \\
\hline \multicolumn{7}{|l|}{ Current marital status: } \\
\hline Married, never divorced/widowed & 34 & 149 & $\mathrm{p}=0.24$ & 46 & 178 & $\mathrm{p}=0.6$ \\
\hline Married, previous divorce/widow & 47 & 130 & $1.61(0.92-2.81)$ & 17 & 85 & $0.79(0.40-1.58)$ \\
\hline Currently widowed/divorced & 11 & 20 & $2.07(0.85-4.99)$ & 13 & 51 & $1.09(0.48-2.45)$ \\
\hline \multirow{2}{*}{\multicolumn{7}{|c|}{ Separated from spouse in past 2 yearsł }} \\
\hline & & & & & & \\
\hline No & 53 & 212 & $\mathrm{p}=0.025$ & 42 & 176 & $\mathrm{p}=0.9$ \\
\hline Yes & 28 & 67 & $1.96(1.10-3.49)$ & 21 & 86 & $1.06(0.55-2.06)$ \\
\hline
\end{tabular}

*Odds ratio adjusted for age and community of residence (one community dropped for analysis of females).

†Significance calculated with test for trend.

$\ddagger$ Only applicable to those currently or previously married.

sexual partners and the prevalence of active syphilis (tables 5 and w6 on website). After adjustment for confounders this association was weaker and non-significant, with an increased risk observed only among the small subgroup of women reporting 10 or more lifetime partners. The number of lifetime partners was not associated with syphilis seroincidence. Few women reported more than two sexual partners during the past year, and although risk in both prevalence and incidence studies was greatest for women reporting three or more partners, these associations were not statistically significant. No significant associations were observed in either study with condom use or casual sexual partners.

The reported age of sexual debut and perceived risk of an STD were significantly associated with the prevalence of active syphilis in women, even after adjustment for confound-

Table 4 Odds ratios for selected biological and behavioural factors, in males

\begin{tabular}{|c|c|c|c|c|c|c|}
\hline \multirow[b]{2}{*}{ Variables } & \multicolumn{3}{|c|}{ Prevalence of active syphilis } & \multicolumn{3}{|c|}{ Incidence of TPHA seroconversion } \\
\hline & Cases & Controls & $\begin{array}{l}\text { Adjusted OR* } \\
(95 \% C I)\end{array}$ & Cases & Controls & $\begin{array}{l}\text { Adjusted OR† } \\
(95 \% \mathrm{CI})\end{array}$ \\
\hline Number participated & 226 & 493 & & 119 & 367 & \\
\hline \multicolumn{7}{|l|}{ Circumcision } \\
\hline No & 187 & 354 & $\mathrm{p}=0.05$ & 101 & 262 & $\mathrm{p}=0.26$ \\
\hline Yes & 39 & 137 & $0.53(0.34-0.84)$ & 18 & 101 & $0.70(0.37-1.32)$ \\
\hline \multicolumn{7}{|l|}{ Sex partners ever $\ddagger$} \\
\hline None or 1 & 14 & 47 & $\mathrm{p}=0.25$ & 4 & 15 & $\mathrm{p}=0.9$ \\
\hline $2-4$ & 28 & 101 & $0.86(0.38-1.95)$ & 14 & 53 & $0.85(0.21-3.38)$ \\
\hline $5-9$ & 42 & 117 & $0.88(0.40-1.91)$ & 23 & 66 & $0.88(0.23-3.38)$ \\
\hline $10-19$ & 57 & 94 & $1.21(0.56-2.62)$ & 23 & 85 & $0.66(0.17-2.58)$ \\
\hline 20 or more & 85 & 134 & $1.16(0.55-2.45)$ & 55 & 148 & $0.91(0.24-3.52)$ \\
\hline \multicolumn{7}{|c|}{ Sex partners in past 1 year $\neq$} \\
\hline None or 1 & 97 & 239 & $\mathrm{p}=0.06$ & 45 & 180 & $\mathrm{p}=0.25$ \\
\hline 2 & 37 & 114 & $0.81(0.50-1.30)$ & 37 & 96 & $1.37(0.77-2.43)$ \\
\hline $3-4$ & 53 & 95 & $1.17(0.75-1.84)$ & 22 & 69 & $1.06(0.55-2.04)$ \\
\hline 5 or more & 38 & 45 & $1.81(1.04-3.16)$ & 15 & 21 & $1.94(0.83-4.50)$ \\
\hline \multicolumn{7}{|l|}{ Ever used a condom } \\
\hline No & 188 & 393 & $\mathrm{p}=0.15$ & 100 & 303 & $\mathrm{p}=0.7$ \\
\hline Yes & 38 & 100 & $0.71(0.45-1.14)$ & 19 & 64 & $0.86(0.45-1.67)$ \\
\hline \multicolumn{7}{|l|}{ Perceived risk of STD } \\
\hline None/slight & 71 & 147 & $\mathrm{p}=0.4$ & 32 & 164 & $\mathrm{p}<0.001$ \\
\hline Moderate & 92 & 226 & $0.88(0.58-1.33)$ & 26 & 82 & $1.63(0.87-3.04)$ \\
\hline High & 47 & 78 & $1.27(0.77-2.11)$ & 49 & 69 & $3.56(2.00-6.33)$ \\
\hline Don't know & 16 & 42 & $0.79(0.39-1.62)$ & 12 & 52 & $1.09(0.48-2.44)$ \\
\hline \multicolumn{7}{|c|}{ Casual sex partner in past year } \\
\hline No & 144 & 328 & $\mathrm{p}=0.7$ & 53 & 181 & $\mathrm{p}=0.3$ \\
\hline Yes & 82 & 165 & $1.07(0.74-1.55)$ & 66 & 186 & $0.76(0.45-1.26)$ \\
\hline \multicolumn{7}{|l|}{ Age at first sex } \\
\hline$<15$ years & 51 & 128 & $\mathrm{p}=0.4$ & 31 & 79 & $\mathrm{p}=0.5$ \\
\hline $15-19$ years & 131 & 282 & $1.06(0.69-1.63)$ & 72 & 239 & $0.88(0.51-1.52)$ \\
\hline $20+$ years & 24 & 35 & $1.59(0.80-3.13)$ & 10 & 27 & $1.56(0.58-4.15)$ \\
\hline
\end{tabular}

^Odds ratio adjusted for age, community of residence, circumcision status, religion, and current marital status.

†Odds ratio adjusted for age, community of residence, education, present job, lived away from the community in past 2 years, perceived risk of STD.

$\ddagger$ Significance calculated with test for trend. 
Table 5 Odds ratios for selected behavioural factors, in females

\begin{tabular}{|c|c|c|c|c|c|c|}
\hline \multirow[b]{2}{*}{ Variables } & \multicolumn{3}{|c|}{ Prevalence of active syphilis } & \multicolumn{3}{|c|}{ Incidence of TPHA seroconversion } \\
\hline & Cases & Controls & $\begin{array}{l}\text { Adjusted OR* } \\
(95 \% \mathrm{CI})\end{array}$ & Cases & Controls & $\begin{array}{l}\text { Adjusted ORt } \\
(95 \% \mathrm{CI})\end{array}$ \\
\hline Number participated & 236 & 555 & & 91 & 341 & \\
\hline \multicolumn{7}{|l|}{ Sex partners ever $\ddagger$} \\
\hline None or 1 & 57 & 188 & $\mathrm{p}=0.4$ & 12 & 46 & $\mathrm{p}=0.8$ \\
\hline $2-4$ & 125 & 264 & $1.03(0.65-1.62)$ & 38 & 147 & $1.08(0.48-2.42)$ \\
\hline $5-9$ & 37 & 83 & $0.93(0.51-1.70)$ & 23 & 79 & $1.31(0.52-3.29)$ \\
\hline 10 or more & 17 & 20 & $2.20(0.90-5.38)$ & 18 & 69 & $1.09(0.42-2.85)$ \\
\hline \multicolumn{7}{|c|}{ Sex partners in past 1 year $\ddagger$} \\
\hline None or 1 & 204 & 494 & $\mathrm{p}=0.9$ & 77 & 296 & $\mathrm{p}=0.7$ \\
\hline 2 & 22 & 42 & $0.92(0.49-1.73)$ & 7 & 35 & $0.71(0.28-1.78)$ \\
\hline 3 or more & 10 & 17 & $1.23(0.46-3.27)$ & 7 & 7 & $1.93(0.53-7.00)$ \\
\hline \multicolumn{7}{|l|}{ Ever used a condom } \\
\hline No & 229 & 539 & $\mathrm{p}=0.75$ & 91 & 326 & \\
\hline Yes & 7 & 16 & $0.85(0.31-2.32)$ & 0 & 15 & -1 \\
\hline \multicolumn{7}{|l|}{ Perceived risk of STD } \\
\hline None/slight & 48 & 149 & $\mathrm{p}<0.001$ & 33 & 143 & $\mathrm{p}=0.14$ \\
\hline Moderate & 98 & 242 & $1.37(0.86-2.18)$ & 17 & 96 & $0.78(0.38-1.64)$ \\
\hline High & 41 & 48 & $3.57(1.91-6.68)$ & 18 & 29 & $2.05(0.92-4.56)$ \\
\hline Don't know & 49 & 116 & $1.46(0.81-2.62)$ & 23 & 73 & $1.41(0.71-2.78)$ \\
\hline \multicolumn{7}{|c|}{ Casual sex partner in past year } \\
\hline No & 210 & 510 & $\mathrm{p}=0.45$ & 61 & 269 & $\mathrm{p}=0.76$ \\
\hline Yes & 26 & 45 & $1.26(0.69-2.32)$ & 29 & 68 & $1.10(0.60-2.02)$ \\
\hline \multicolumn{7}{|l|}{ Age at first sex } \\
\hline$<15$ years & 72 & 120 & $\mathrm{p}=0.03$ & 22 & 82 & $\mathrm{p}=0.13$ \\
\hline $15-19$ years & 118 & 311 & $0.63(0.42-0.93)$ & 65 & 209 & $1.00(0.54-1.83)$ \\
\hline $20+$ years & 9 & 35 & $0.44(0.19-1.02)$ & 1 & 22 & $0.18(0.02-1.52)$ \\
\hline
\end{tabular}

*Odds ratio adjusted for age, community of residence, education, age at first sex, perceived risk of STD, current marital status. †Odds ratio adjusted for age, community of residence, lived away from the community in the past 2 years (one community dropped). $¥$ Significance calculated with test for trend.

$\$ 95 \%$ CI for ever use of condom is not estimable for the incidence study.

ing factors. For reported sexual debut, the highest risk was found among women who became sexually active before age 15 , and the increased risk was similar across all age groups (data not shown). Similar trends were observed for seroincidence, but these were not statistically significant.

\section{Discussion}

These studies were conducted in a rural African population where syphilis is highly endemic. Around 15\% are TPHA positive, indicating that at least this proportion have had a current or previous infection. The overall prevalence of active syphilis is around $8 \%$, and of high titre active syphilis about $6 \%$. These results accord with data from previous studies in the same region. ${ }^{10131621}$ The annual incidence of TPHA seroconversion in these rural communities was about $1.8 \%$.

Our data reveal some interesting variations by age and sex. In men, TPHA seroincidence is around $2 \%$ at all ages, leading to a steady increase in TPHA prevalence to a peak of around $20 \%$ at age $35-44$. In contrast, there is a very high incidence among young women aged 15-19 which falls to lower levels from age 20 upwards. Consequently, the prevalence of active syphilis is considerably higher among young women than their male peers, a finding that has also been observed for HIV, herpes simplex virus type 2 (HSV-2), and other STDs. ${ }^{21}{ }^{22}$ Clearly young women are at very high risk, and this is of special concern as a high proportion of women become pregnant and commence childbearing before reaching 20 years of age. In both sexes, from age 20, the prevalence of active syphilis remains relatively stable in both sexes, but with increasing age there is a decline in both the proportion with high titre active syphilis, and the ratio of active syphilis to TPHA positivity. This presumably reflects a balance between newly acquired infections, the decline of RPR titres in late latent syphilis, and in older age groups an increasing proportion of old infections that are TPHA positive and RPR negative. Interestingly, TPHA seroincidence is lower overall in women than men, while the prevalence of active syphilis is higher. This would suggest that the duration of active syphilis is longer in women, possibly because more women are asymptomatic and go untreated for longer periods.

Data from these communities show marked geographical variations in both the incidence and prevalence of serological syphilis, with much lower rates in communities on the islands of Lake Victoria. Although the data are inconclusive, these patterns may reflect variations in sexual behaviour, and in particular in the extent of high risk sexual partnerships typical of "core groups" which may be associated with higher rates of syphilis and HIV transmission. ${ }^{23}$ Statistical analyses in the current study were adjusted for community of residence, and so were not confounded by geographical variations.

This study relied on the use of serological tests for syphilis. The RPR and TPHA tests are generally used for the diagnosis of syphilis in symptomatic patients, or as screening tests among groups at risk. Both tests have limitations as epidemiological tools. ${ }^{24}$ In the prevalence study, active syphilis cases were defined as those TPHA positive and RPR positive with any titre. This definition will include those with infectious (primary and secondary) syphilis, but also cases of untreated latent syphilis, as well as some who have been successfully treated in whom the RPR can remain positive for a long period. It may also include some 
individuals who are TPHA positive as a result of a past infection, and who give a biological false positive result on RPR testing due, for example, to malaria or other infections. In the incidence study, TPHA seroconversion was used to define cases. While this marker should accurately detect incident cases of syphilis, ${ }^{25}$ it can only be used in those initially TPHA negative and thus fails to capture new episodes of syphilis among those previously infected.

Although serological tests for treponemal infection cannot distinguish venereal syphilis from yaws or endemic syphilis, clinical experience indicates that the latter have not been recorded in Tanzania for many years. This, together with the high incidence of seroconversion observed among young men and women in our study, and the association of seropositivity with indices of sexual behaviour, suggest that serology in this population largely reflects sexually transmitted syphilis.

There are two other possible sources of bias in this study. Firstly, not all subjects selected for the case-control studies were successfully interviewed. Participation rates were $70-80 \%$, the main reason for non-participation being absence from the community at the time of the survey. This may imply that the more mobile, and possibly more sexually active, members of the community were underrepresented in the case-control studies, but it seems unlikely that risk factor associations recorded among those successfully interviewed will have been biased appreciably. Secondly, the data on sexual behaviour relied on interview data, and although questionnaires were carefully designed and pretested, and although the interviewers received intensive training and supervision, responses may have been biased by recall errors, or intentional or unintentional misreporting of behaviour. Assuming that misclassification was non-differential, such errors will have diluted true associations of behavioural risk factors with serological syphilis.

The prevalence of active syphilis depends both on the incidence of infection and on its duration. Variables associated with active syphilis may therefore reflect risk factors for infection, or factors related to effective treatment. Of the sociodemographic factors presented here higher education for women, and travel to Mwanza town in both sexes, were associated with reduced prevalence of active syphilis, while traditional religion was associated with increased prevalence among men. These associations may reflect differences in sexual exposure or in treatment seeking behaviour for symptomatic syphilis.

In contrast, the associations observed with marital status are likely to reflect influences on sexual exposure to syphilis infection. The main finding was of increased prevalence among men and women who were currently or previously divorced or widowed. Men married to women who were previously divorced or widowed were also at increased risk. These findings are in accord with other studies showing that divorced and widowed men and women are more likely to have multiple sexual partners, and are therefore at higher risk of infection. ${ }^{26}{ }^{27}$ Marital dissolution is common in this population, and $20 \%$ of prevalent syphilis infections were attributable to divorce or widowhood in our study.

Additional factors associated with syphilis seroincidence in men included lower educational attainment and a farming occupation. These associations may reflect differences in risk behaviour, or lower access to effective treatment among the sexual partners of men with a more "traditional" lifestyle. The higher incidence among men and women who had lived away from their communities accords with other data showing that mobility and migration are associated with a higher prevalence of HIV and other STDs. ${ }^{12} 28$

Of the "proximate" risk factors, some showed a clear association with syphilis, while other associations were more equivocal. Around $20-30 \%$ of men were circumcised in this study population. Both the prevalence of active syphilis and seroincidence were lower in circumcised men, and the association with active syphilis was strongly significant. An estimated $36 \%$ of prevalent syphilis infections among men were attributable to lack of circumcision. This finding accords with other studies showing that male circumcision is protective against HIV infection and genital ulcer disease. ${ }^{1329}$ There is increasing evidence from epidemiological studies that circumcision may has an important role in explaining heterogeneities in the HIV epidemic in different parts of Africa. It may offer protection against HIV acquisition both directly, and also indirectly by reducing the prevalence of syphilis and other ulcerative diseases that enhance HIV transmission. Consideration is now being given to the acceptability and feasibility of programmes to provide easier access to safe facilities for male circumcision in populations where many men are uncircumcised. If successful, such programmes might have an appreciable impact on syphilis transmission as well as HIV.

After adjustment for confounders, no significant associations were seen with reported lifetime partners in either sex, and this is perhaps unsurprising given that both syphilis markers are likely to be most closely related to recent sexual exposure. In men, there was a trend to higher prevalence and incidence among those reporting five or more partners during the past year. Moreover syphilis showed strong associations with perceived risk of STD in both sexes and this did reduce the association between syphilis and the reported number of sexual partners in men, but not in women. Perceived risk is a complex variable that may incorporate both the subject's own risk behaviour, and their perceptions about the risk they are exposed to as a result of the sexual behaviour of their spouses or other partners.

The prevalence of active syphilis was higher among women with an earlier age of sexual debut and this reduced the association between syphilis and the number of sexual partners in women. Early age of sexual debut may be associated with the establishment of lifelong patterns of behaviour, such as higher rates of partner change in later life. Alternatively, 
higher prevalence in those with early debut may reflect a longer duration of exposure and thus a higher cumulative risk of infection.

What lessons for syphilis control can be drawn from this study? Firstly, the prevalence of syphilis clearly remains at unacceptably high levels in this rural Tanzanian population. Our data show that at least $20 \%$ of $35-44$ year old men and women have had past or current infections, and around $6 \%$ of all adults have high titre active syphilis. Although the Mwanza intervention trial has shown that improved syndromic management of STDs in rural health clinics reduced the prevalence of active syphilis by an estimated $30 \%$, this intervention was clearly not sufficient by itself to achieve adequate control of syphilis. ${ }^{16}$ In the present study only $19 \%$ of TPHA seroconverters reported symptoms, and this is consistent with other studies. ${ }^{10}$ Asymptomatic patients are unlikely to have sought treatment, and those who do recognise symptoms often seek treatment from traditional healers or private pharmacies. ${ }^{30}$

Clearly more intensive strategies for syphilis control are needed, both to reduce the large burden of morbidity associated with syphilis and to reduce its cofactor effect on HIV transmission. Three main strategies are currently available. Firstly, continued efforts should be made to promote prompt treatment seeking behaviour, and to ensure that effective treatment is available and easily accessed by symptomatic patients and their contacts. Secondly, with a prevalence of active syphilis of nearly $10 \%$ among women of reproductive age, it is essential that all women attending for antenatal care should be screened and treated. Thirdly, efforts to achieve primary prevention through promotion of safer sexual behaviour must be strengthened.

One of the most alarming findings of this study was the very high incidence and prevalence of syphilis among young women aged $15-19$ years. Nearly $7 \%$ of young women seroconverted over 2 years of follow up, and since the more mobile members of the population may have been missed this may be an underestimate. Moreover, we found a significant association between syphilis prevalence and early age of sexual debut. These findings support the implementation of educational programmes among adolescents to encourage safer sexual behaviour and improved treatment seeking behaviour. Adolescent sexual health education programmes could be implemented through the school curriculum, and there is an urgent need for rigorously designed trials to evaluate the effectiveness of such programmes. A randomised trial of such an intervention is now in progress in Mwanza Region.

We wish to thank the principal secretary, Ministry of Health, the manager of the National AIDS Control Programme, and the director general of the National Institute for Medical Research, director general of the National Institute for Medical Research,
Tanzania, for permission to carry out and publish the results of Tanzania, for permission to carry out and publish the results of
this study. We appreciate the assistance and hard work of the this study. We appreciate the assistance and hard work of the
regional, district, ward, and community leaders and of the study reams. We acknowledge the patience and time given by the study teams. We acknowledge the patience and time given by the study participants and their families. We thank Beryl West and Jan
Cornelisson for their help with laboratory work and David Ross for his helpful comments in the writing of the paper. The study was made possible through the financial support of the Commission of the European Communities (EC Life Sciences and Technologies for Developing Countries programme), the EC AIDS Task Force, the Overseas Development Administration of the UK (now the Department for International Development), the Medical Research Council of the UK, and the German Centre of International Migration and Development.

Contributors: RH, DM, HG, and AG were involved in the concept and design of the study; FM, AG, PM, KM, JT, and HG supervised and completed the study field work; JM and JC performed all the laboratory tests with advice from DM; JT, HG, and RH performed data management and statistical analysis; the paper was written by JT and $\mathrm{RH}$ with comments, suggestions, and advice from all of the authors.

There is no conflict of interest between this paper and any of the authors.

1 Sparling PF. Natural history of syphilis. In: Holmes KK, Sparling PF, Mardh PA, et al, eds. Sexually transmitted diseases. Chapter 34. New York: MacGraw Hill, 1999.

2 Gerbase ASC, Rowley JT, Heymann DHL, et al. Global prevalence and incidence estimates of selected curable prevalence and incidence estimates of selected

3 Gerbase AC, Rowley JT, Mertens TE. Global epidemiology of sexually transmitted diseases. Lancet 1998;351(suppl III):SIII $2-4$.

4 DeSchryver A, Meheus A. Epidemiology of sexually transmitted diseases: the global picture. Bull World Health Organ 1990;68:639-54.

5 Over M, Piot P. HIV infection and sexually transmitted diseases. In: Jamison, Mosley, Measham, Bobadilla, eds. Disease control priorities in developing countries. New York: OUP, 1993.

6 Ratnam AV, Din SN, Hira SK, et al. Syphilis in pregnant women in Zambia. Br F Vener Dis 1982;58:355-8.

7 McDermott J, Steketee R, Larsen S, et al. Syphilisassociated perinatal and infant mortality in rural Malawi. Bull World Health Organ 1993;71:773-80.

8 Fleming DT, Wasserheit JN. From epidemiological synergy to public health policy and practice: the contribution of other sexually transmitted diseases to sexual transmission of HIV infection. Sex Transm Inf 1999;75:3-17.

9 Cohen MS. Sexually transmitted diseases enhance HIV transmission: no longer a hypothesis. Lancet 1998; 351(suppl III):SIII5-7.

10 Mosha F, Nicoll A, Barongo L, et al. A population based study of syphilis and sexually transmitted disease syndromes in north-western Tanzania. 1. Prevalence and Incidence. Genitourin Med 1993;69:415-20.

1 Klouman E, Masenga EJ, Sam NE. Serological markers for treponemal infection in children in rural Kilimanjaro, Tanzania: evidence of syphilis or non-venereal treponematoses? Genitourin Med 1997;73:522-7

12 Killewo JZ, Sandstrom A, Bredberg-Raden U, et al. Prevalence and incidence of syphilis and its association with HIV-1 infection in a population-based study in the Kagera region of Tanzania. Int F STD AIDS 1994;5:42431 .

13 Newell J, Senkoro K, Mosha F, et al. A population-based study of syphilis and sexually transmitted disease synstudy of syphilis and sexualy transmitted disease synhealth seeking behaviour. Genitourin Med 1993;69:421-6.

14 Temmerman M, Mohamed AF, Fransen L. Syphilis intervention in pregnancy: an opportunity to improve reproductive and child health in Kenya. Health Policy Planning 1993;8:122-7.

5 Grosskurth H, Mosha F, Todd J, et al. Impact of improved treatment of sexually transmitted diseases on HIV infection in rural Tanzania: randomised controlled trial. Lancet 1995;346:530-6.

16 Mayaud P, Mosha F, Todd J, et al. Improved treatment services significantly reduce the prevalence of sexually transmitted diseases in rural Tanzania: results of a randomized controlled trial. AIDS 1997;11:1873-80.

17 Hayes R, Grosskurth H, ka-Gina G. Impact of improved treatment of sexually transmitted diseases on HIV infection. Lancet 1995;346:1159-60.

18 Quigley M, Munguti K, Grosskurth H, et al. Sexual behaviour patterns and other risk factors for HIV infection in iour patterns and other risk factors for HIV infection in
rural Tanzania: a case-control study. AIDS 1997;11:23748.

19 Hayes R, Mosha F, Nicoll A, et al. A community trial of the impact of improved STD treatment on the HIV epidemic in rural Tanzania: 1. Design. AIDS 1995;9:919-26.

20 Bruzzi P, Green SB, Byar DP, et al. Estimating the population attributable risk for multiple risk factors using case-control data. Am f Epidemiol 1985;122:904-14.

21 Grosskurth H, Mosha F, Todd J, et al. A community trial of the impact of improved STD treatment on the HIV epidemic in rural Tanzania: 2. Baseline survey results. AIDS 1995;9:927-34.

22 Obasi A, Mosha F, Quigley M, et al. Antibody to herpes simplex virus type 2 as a marker of sexual risk behaviour in rural Tanzania. F Infect Dis 1999;179:16-24.

23 Jensen H, Mosha F, Williams L, et al. Geographic variation in the prevalence of HIV and other sexually transmitted diseases: lower risk in lake-island communities in Mwanza Region, Tanzania. f Acquir Immune Defic Syndr Hum Retrovirol (in press). 
24 Thomas DL, Quin TC. Serological testing for sexually transmitted diseases. Infect Dis Clin North Am 1993;7:793-824.

25 Augenbraun M, Rolf R, Johnson R, et al. Treponemal specific tests for the serodiagnosis of syphilis. Sex Transm Dis 1998;25:549-5

26 Munguti K, Grosskurth H, Newell J, et al. Patterns of sexual behaviour in a rural population in North-Western Tanzania. Soc.Sci.Med 1997;44:1553-61

27 Mnyika KS, Klepp K-I, Kvale G, et al. Prevalence of HIV-1 infection in urban, semi-urban and rural areas in Arusha region, Tanzania. AIDS 1994;8:1477-81.
28 Nunn AJ, Wagner HU, Kamali A, et al. Migration and HIV-1 seroprevalence in a rural Ugandan population. AIDS 1995; 9:503-6.

29 Moses S, Bailey RC, Ronald AR. Male circumcision: assessment of health benefits and risks. Sex Transm Inf 1998;74:368-73.

30 Rajani R, Mugeye K, Mayaud P. Determinants of treatment seeking behaviour for sexually transmitted infections in Mwanza, Tanzania. Presentation to ISSTD, Seville, 1997 (Abstract No S15). 